\title{
REVIEW OF EFFECTIVE METHODOLOGIES FOR OPTIMIZATION OF PUMP DISCHARGE CONDITIONS TO ENHANCE OPERATIONAL EFFICIENCY
}

\author{
Sumant Deshpande \\ Assistant Professor, Department of Mechanical Engineering, \\ Sandipani Technical Campus-Faculty of Engineering, Maharashtra, India

\section{Dr Mohan Buke} \\ Professor, Department of Mechanical Engineering, \\ Sandipani Technical Campus-Faculty of Engineering, Maharashtra, India
}

\begin{abstract}
Almost all industries has a Large use of Cetrifugal Pumps in all capacities. Usually most of the Manufacturing units deploy centrifugal pumps at various operations like Chilled water ,solution transfer, effluents, water ,chemicals ,etc .The Pump sizing Generally Designed for Higher Head and Flows considering Peak conditions during the operation. However most of the pump, due to incorrect assumption fall in low efficiency zone because of Lesser actual Head or Flow requirement. The Review encompasses the three basic methods and their merits and demerits viz 1. Throttling 2.Use of VSD (Variable speed Drive 3.Impeller trimming .The strategy is selected on the basis of the application and load variation and facrots described Here further
\end{abstract}

Key words: Centrifugal Pump, Efficiency, VSD, Impeller Trimming, Throttling, Pump Discharge

Cite this Article: Sumant Deshpande and Mohan Buke, Review of Effective Methodologies for Optimization of Pump Discharge Conditions to Enhance Operational Efficiency, International Journal of Industrial Engineering Research and Development, 7(1), 2016, pp. 35-40. https://iaeme.com/Home/issue/IJIERD?Volume $=7 \&$ Issue $=1$

\section{INTRODUCTION}

The Pump is designed say at Full sized impeller (Fig A) The actual site conditions or even in varyi load the Efficiency drops and Power Consumption increases the process of arriving at the affinity laws assumes that the two operating points that are being compared are at the same efficiency. The relationship between two operating points, say 1 and 2, depends on the shape of the system curve (Figure B). The points that lie 
on system curve A will all be approximately at the same efficiency. Whereas the points that lie on system curve B are not. The affinity laws do not apply to points that belong to system curve B. System curve B describes a system with a relatively high static head vs. system curve A which has a low static head.

$$
\frac{P_{1}}{P_{2}}=\frac{n_{1}^{3} D_{1}^{3}}{n_{2}{ }^{3} D_{2}{ }^{3}}, \frac{Q}{Q_{2}}=\frac{D_{1}^{3}}{D_{2}{ }^{3}}, \frac{H_{1}}{H_{2}}=\frac{D_{1}{ }^{2}}{D_{2}{ }^{2}}
$$

\section{PUMP IMPELLER TRIMMING}
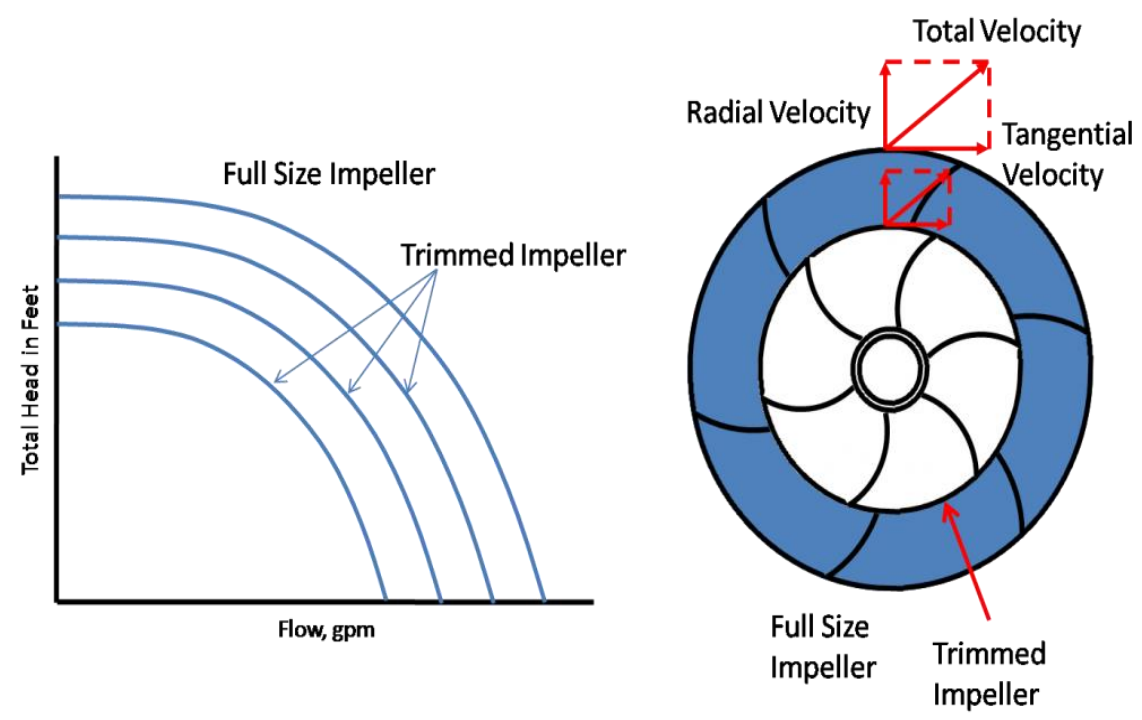

Figure 1

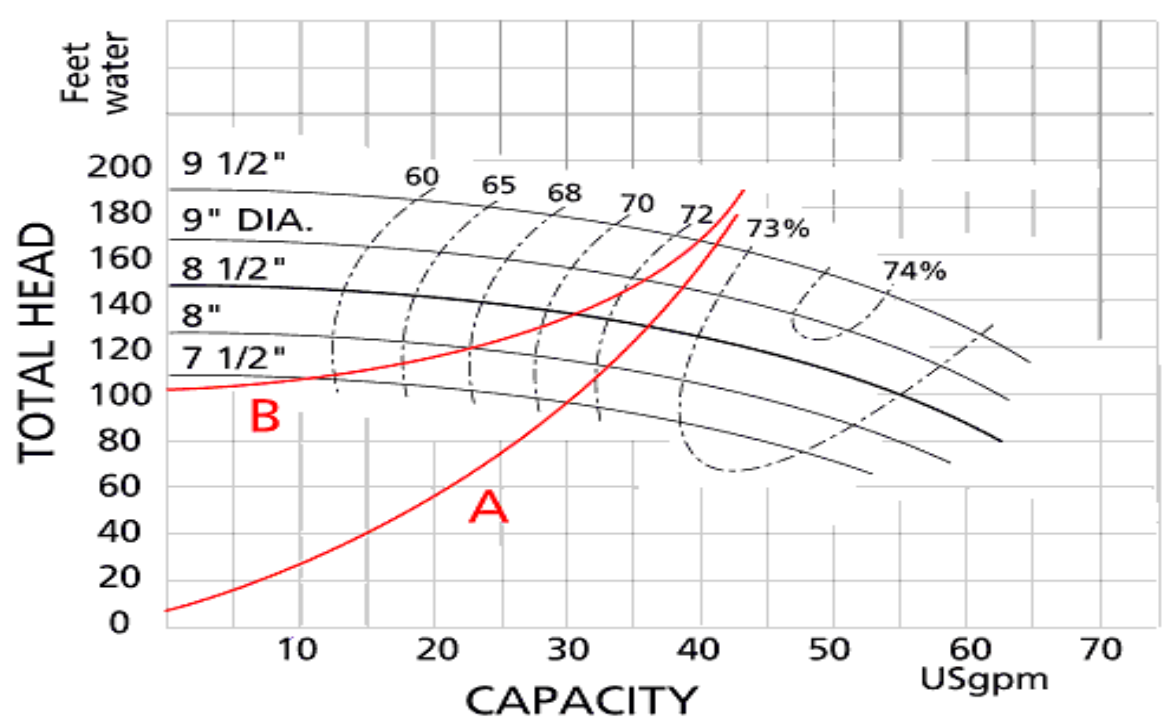

Figure 2 


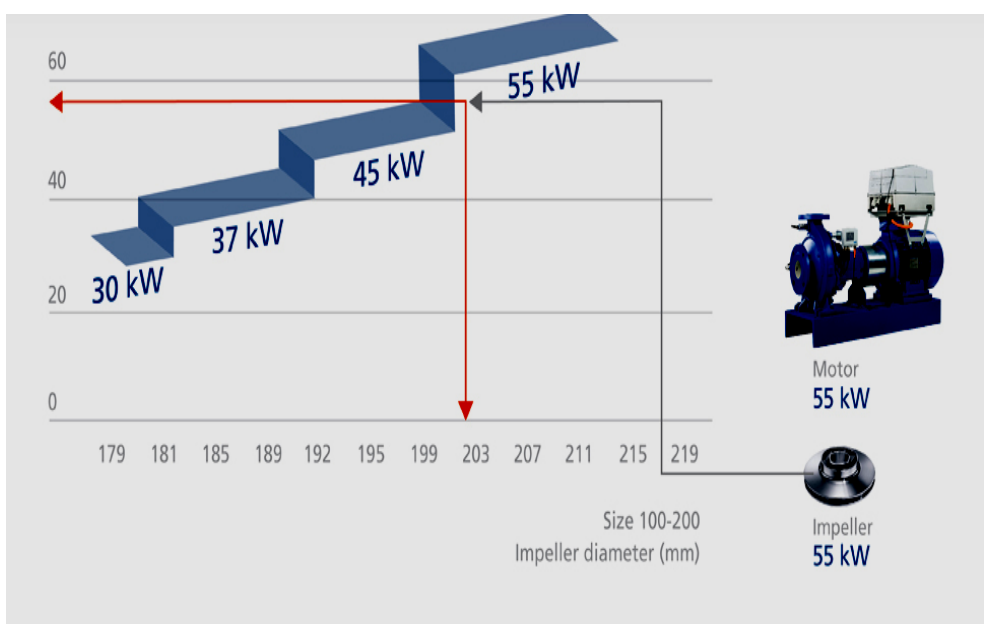

Figure 3

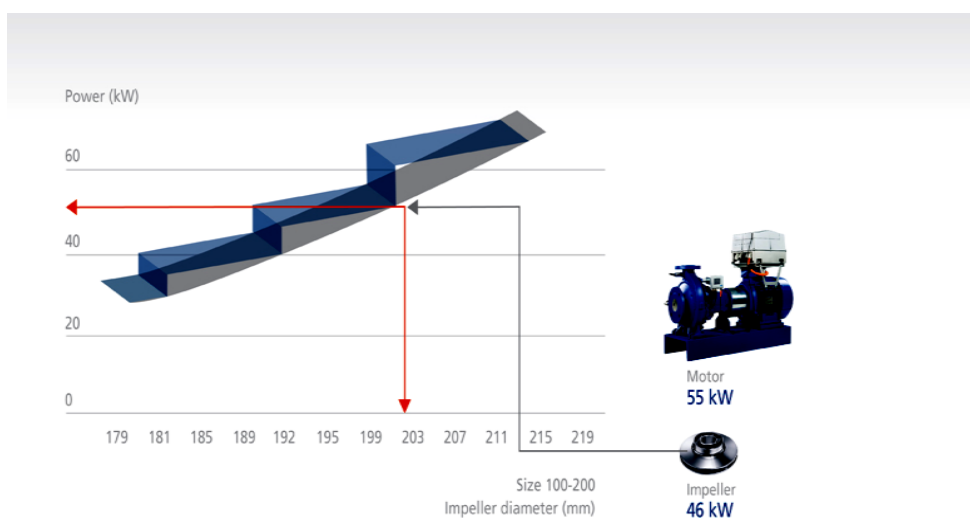

Figure 4

Thus, the designed conditions changed. The trimming Helps to reduce power absorption by the formulae given as Pump laws

A case shown in Fig C as $55 \mathrm{kw}$ absorption with Impeller size 215 to 219, It reduces to $46 \mathrm{KW}$ with $211-215$

The flow and Head are reduces as per duty conditions.

Table 1

\begin{tabular}{|l|c|c|c|c|c|}
\hline & $\begin{array}{c}\text { Impeller Dia } \\
\mathbf{m m}\end{array}$ & $\mathbf{Q 1}\left(\mathbf{~ m}^{\mathbf{3}} / \mathbf{S}\right)$ & $\mathbf{H}$ & $\mathbf{P}$ & Effciency \\
\hline Before Trimming & 219 & 0.8 & $20 \mathrm{~m}$ & 56 & $65 \%$ \\
\hline After Trimming & 203 & 0.6 & $18 \mathrm{~m}$ & 45 & $75 \%$ \\
\hline
\end{tabular}

However this sytem applicable where fix conditions are available at load side In variable conditions it fails to creat Head or Discharge Hence not recommended.

\section{Advantages}
A. Low cost solution
B. Efficiency Improves Drastically
C. Maintenance of Pump Reduces as it operates at best Operating Point 


\section{Disadvantages}

A. Can be used for fix load size only

B. Once trimmed impleller cant use for another application

\section{USE OF VSD}

The VSD, use is another method to achieve Best operating Point Changing pump impeller diameter also effectively changes the duty point in a given system, and at low cost, but this can be used only for permanent adjustment to the pump curve and is not discussed further as a control method. For systems where friction loss predominates, reducing pump speed moves the intersection point on the system curve along a line of constant efficiency (see Figure E). The operating point of the pump, relative to its best efficiency point, remains constant and the pump continues to operate in its ideal region. The Affinity Laws are obeyed, which means that there is a substantial reduction in power absorbed accompanying the reduction in flow and head, making variable speed the ideal control method.

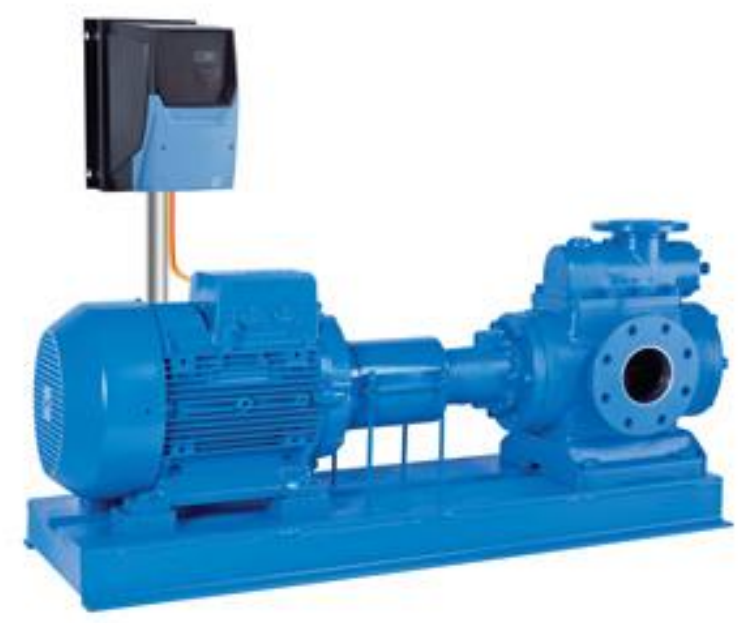

Figure 5

If the diameter is fixed they become:

$$
\frac{Q}{Q_{2}}=\frac{n_{1}}{n_{2}} \quad \frac{H_{1}}{H_{2}}=\frac{n_{1}{ }^{2}}{n_{2}{ }^{2}} \quad \frac{P_{1}}{P_{2}}=\frac{n_{1}{ }^{3}}{n_{1}{ }^{3}}
$$

Thus the Head, Discharge and Power Reduces as per the requirement

\section{Advantages}
A. Exact Duty Point Achived
B. Energy saving can be in tune $30 \%$ to $50 \%$
C. The Condition can be changed Anytime
D. Maintenance of Pump Reduces as it operates at best Operating Point

\section{Disadvantages}
A. High Cost application
B.NPSH restricted at Low speed
C. Use of Throttling Device (Valve) 
The Most Undesired Method to change the pump Discharge conditions is by throttling

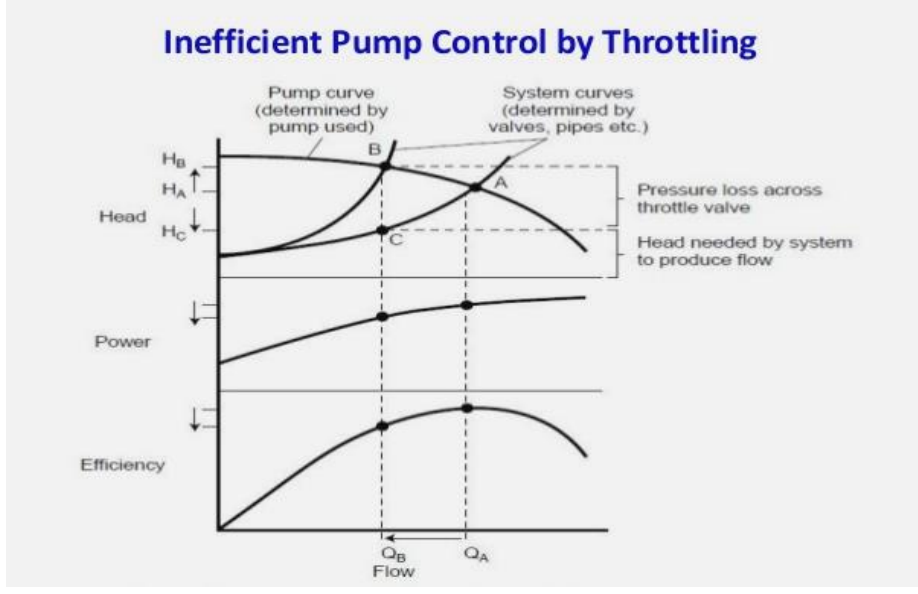

Figure 6

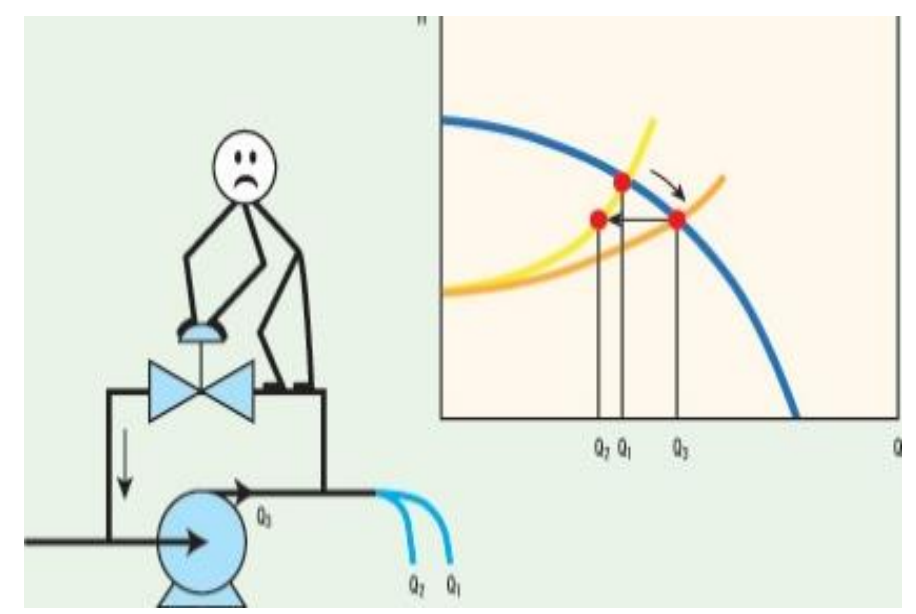

Figure 6

Throttling increases the system head and hence the Discharge reduces. But with the head increase the Power increases with cube hence undesired power lost in throttling

\section{Advantages}

A. Easy to change

\section{Disadvantages}

A. High Power Loss

B. High Maintenance

\section{CONCLUSION}

The strategies explained above are largly depend upon the Load side Management However as a Thumb rule the fixed system demand Impeller trimming is low cost and efficient operation

The VSD is most efficient way to Regulate the Discharge in Dynamic varying Load where the demand side is varying continuously.However the system installation cost is high hence Judicious use is key to deploy 
Review of Effective Methodologies for Optimization of Pump Discharge Conditions to Enhance Operational Efficiency

Pump Throttling is most Inefficient way to Control discharge conditions, Not only it waste the energy, it cant assure the correct regulation

Following are some diagnostics used as references

Table 2

\begin{tabular}{|c|c|c|}
\hline Symptom & Likely Reason & Best Solutions \\
\hline Throttle valve-controlled systems & Oversized pump & $\begin{array}{l}\text { Trim impeller, smaller impeller, } \\
\text { variable speed drive, two speed } \\
\text { drive, lower rpm }\end{array}$ \\
\hline $\begin{array}{l}\text { Bypass line (partially or } \\
\text { completely) open }\end{array}$ & Oversized pump & $\begin{array}{l}\text { Trim impeller, smaller impeller, } \\
\text { variable speed drive, two speed } \\
\text { drive, lower rpm }\end{array}$ \\
\hline $\begin{array}{l}\text { Multiple parallel pump system } \\
\text { with the same number of pumps } \\
\text { always operating }\end{array}$ & $\begin{array}{l}\text { Pump use not } \\
\text { monitored or controlled }\end{array}$ & Install controls \\
\hline $\begin{array}{l}\text { Constant pump operation in a } \\
\text { batch environment }\end{array}$ & Wrong system design & On-off controls \\
\hline $\begin{array}{l}\text { High maintenance cost (seals, } \\
\text { bearings) }\end{array}$ & $\begin{array}{l}\text { Pump operated far } \\
\text { away from BEP }\end{array}$ & $\begin{array}{l}\text { Match pump capacity with } \\
\text { system requirement }\end{array}$ \\
\hline
\end{tabular}

Diagnostic Table ${ }^{[3]}$

\section{REFERENCES}

[1] The Pump Handbook by McGraw-Hill,

[2] The Pump Handbook by McGraw-Hill,

[3] The Bureau of Energy Efficiency, India, E notes

[4] V. Muralidharan, V. Sugumaran, P. Shanmugam \& K. Sivanathan. Artificial Neural Network Based Classification for Monoblock Centrifugal Pump Using Wavelet Analysis, International Journal of Mechanical Engineering and Technology, 1(1), 2010, pp. 28-37.

[5] Shalin Marathe and Rishi Saxena. Numerical Analysis on Effect of Exit Blade Angle on Cavitation In Centrifugal Pump, International Journal of Mechanical Engineering and Technology, 4(3), 2013, pp. 359-366.

[6] Jyothi P.N, A. Shailesh Rao, M.C. Jagath, and K. Channakeshavalu. Understanding The Melt Flow Behaviour of Za Alloys Processed Through Centrifugal Casting, International Journal of Mechanical Engineering and Technology, 4(1), 2013, pp. 163-172. 